\title{
Feasibility and Testing of Additive Manufactured Components
}

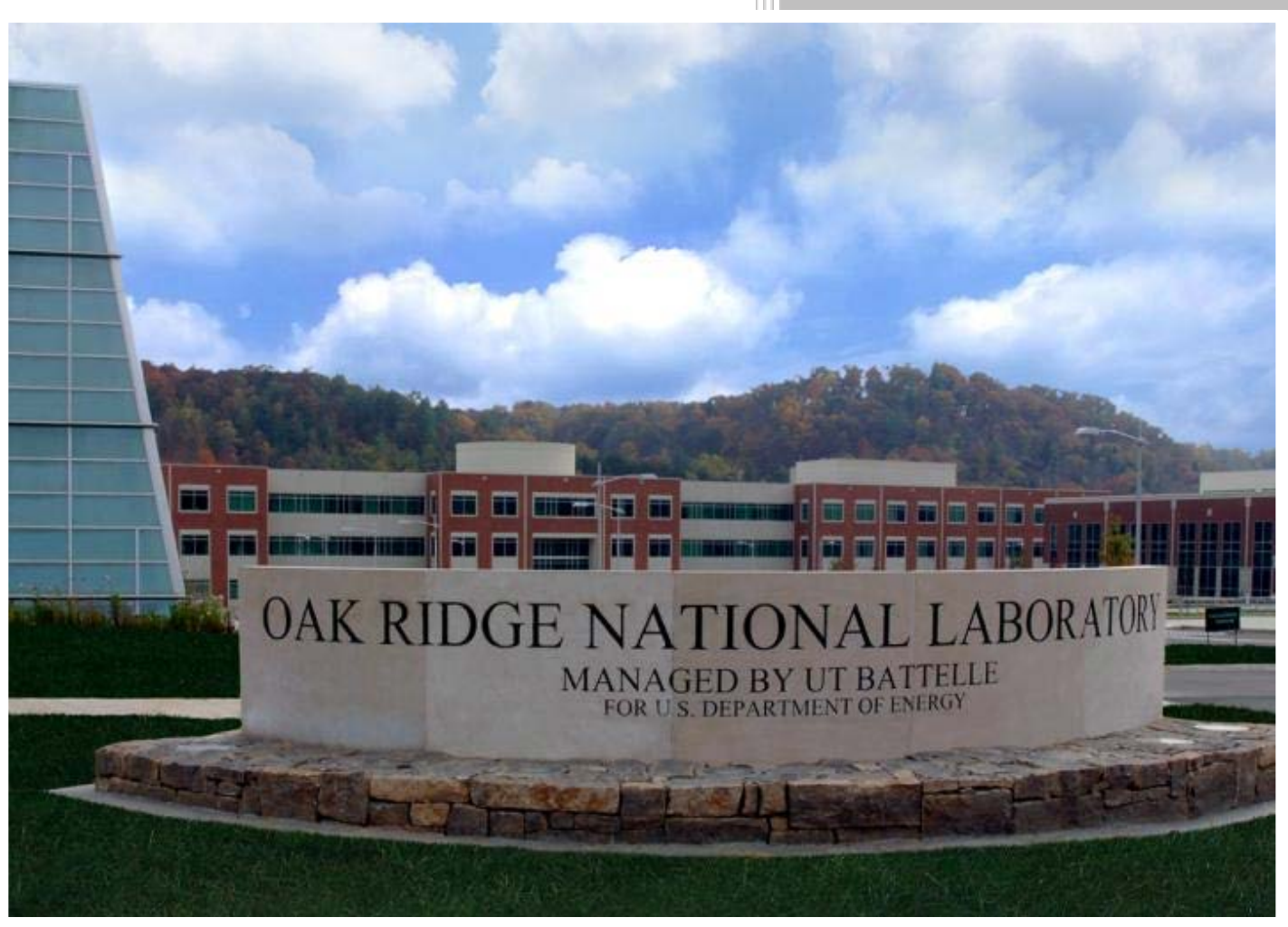

Ryan Dehoff

August 29, 2016

CRADA FINAL REPORT

NFE-15-05564

Approved for Public Release

Distribution is Unlimited.

This report includes work performed on an ITAR

component but does not disclose any technical data 


\title{
DOCUMENT AVAILABILITY
}

Reports produced after January 1, 1996, are generally available free via US Department of Energy (DOE) SciTech Connect.

Website http://www.osti.gov/scitech/

Reports produced before January 1, 1996, may be purchased by members of the public from the following source:

\author{
National Technical Information Service \\ 5285 Port Royal Road \\ Springfield, VA 22161 \\ Telephone 703-605-6000 (1-800-553-6847) \\ TDD 703-487-4639 \\ Fax 703-605-6900 \\ E-mail info@ntis.gov \\ Website http://www.ntis.gov/help/ordermethods.aspx
}

Reports are available to DOE employees, DOE contractors, Energy Technology Data Exchange representatives, and International Nuclear Information System representatives from the following source:

Office of Scientific and Technical Information

PO Box 62

Oak Ridge, TN 37831

Telephone 865-576-8401

Fax 865-576-5728

E-mail reports@osti.gov

Website http://www.osti.gov/contact.html

This report was prepared as an account of work sponsored by an agency of the United States Government. Neither the United States Government nor any agency thereof, nor any of their employees, makes any warranty, express or implied, or assumes any legal liability or responsibility for the accuracy, completeness, or usefulness of any information, apparatus, product, or process disclosed, or represents that its use would not infringe privately owned rights. Reference herein to any specific commercial product, process, or service by trade name, trademark, manufacturer, or otherwise, does not necessarily constitute or imply its endorsement, recommendation, or favoring by the United States Government or any agency thereof. The views and opinions of authors expressed herein do not necessarily state or reflect those of the United States Government or any agency thereof. 


\title{
Materials Science and Technology Division Advanced Manufacturing Office
}

\section{Feasibility and Testing of Additive Manufactured Components}

\author{
Authors \\ Ryan Dehoff \\ Ed Hummelt \\ Lyudmila Solovyeva
}

Date Published:

August 29, 2016

\author{
Prepared by \\ OAK RIDGE NATIONAL LABORATORY \\ Oak Ridge, Tennessee 37831-6283 \\ managed by \\ UT-BATTELLE, LLC \\ for the \\ US DEPARTMENT OF ENERGY \\ under contract DE-AC05-00OR22725
}

Approved For Public Release 


\section{CONTENTS}

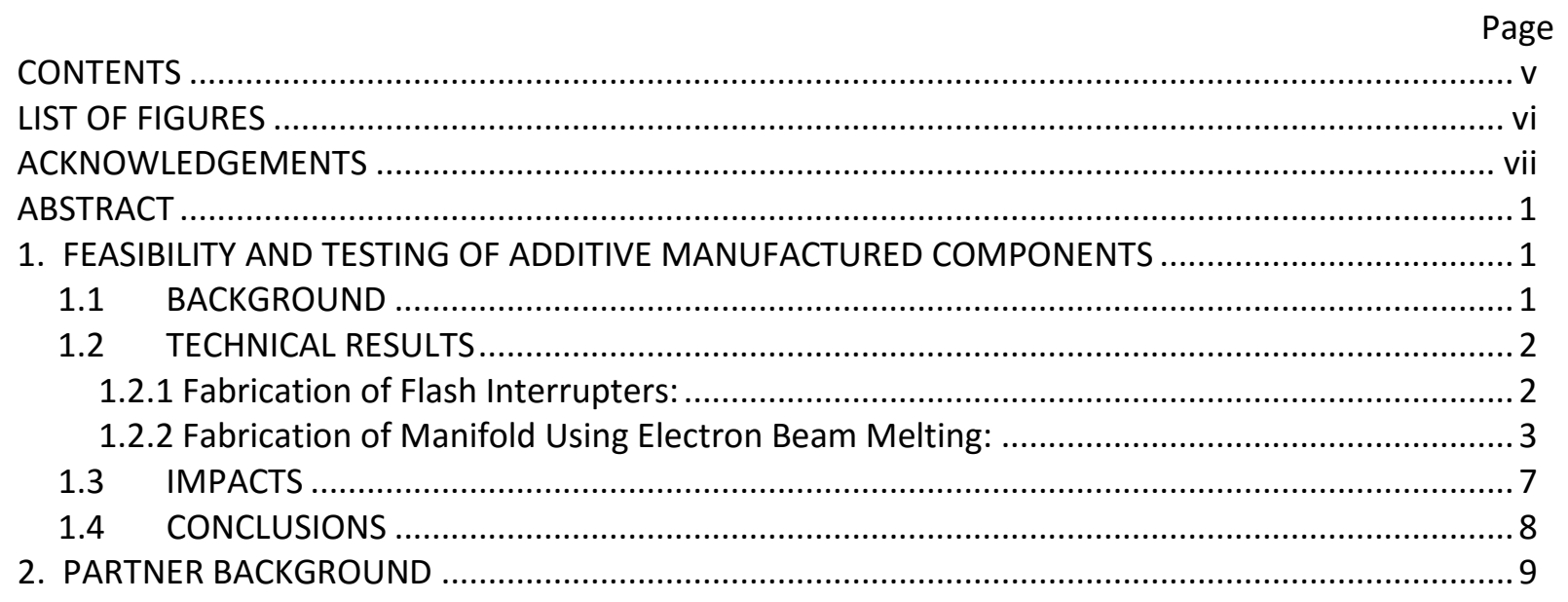




\section{LIST OF FIGURES}

Figure 1: Minimum wall spacing achievable in the Renishaw laser powder bed system using 316L

stainless steel powder.

3

Figure 2: Layout within the EBM chamber for the manifold, tensile bars, and geometric test artifact 4

Figure 3: Microstructural analysis of tensile samples for porosity before and after HIP................... 6

Figure 4: Mechanical properties of EBM processed Ti-6AI-4V samples ........................................... 7 


\section{ACKNOWLEDGEMENTS}

This CRADA NFE-15-05564 was conducted as a Technical Collaboration project within the Oak Ridge National Laboratory (ORNL) Manufacturing Demonstration Facility (MDF) sponsored by the US Department of Energy Advanced Manufacturing Office (CPS Agreement Number 24761). Opportunities for MDF technical collaborations are listed in the announcement "Manufacturing Demonstration Facility Technology Collaborations for US Manufacturers in Advanced Manufacturing and Materials Technologies" posted at http://web.ornl.gov/sci/manufacturing/docs/FBO-ORNLMDF-2013-2.pdf. The goal of technical collaborations is to engage industry partners to participate in short-term, collaborative projects within the Manufacturing Demonstration Facility (MDF) to assess applicability and of new energy efficient manufacturing technologies. Research sponsored by the U.S. Department of Energy, Office of Energy Efficiency and Renewable Energy, Advanced Manufacturing Office, under contract DE-AC05-00OR22725 with UT-Battelle, LLC. 



\begin{abstract}
This project focused on demonstrating the ability to fabricate two parts with different geometry: an arc flash interrupter and a hydraulic manifold. Eaton Corporation provided ORNL solid models, information related to tolerances and sensitive parameters of the parts and provided testing and evaluation. ORNL successfully manufactured both components, provided cost models of the manufacturing (materials, labor, time and post processing) and delivered test components for Eaton evaluation. The arc flash suppressor was fabricated using the Renishaw laser powder bed technology in CoCrMo while the manifold was produced from Ti-6Al-4V using the Arcam electron beam melting technology. These manufacturing techniques were selected based on the design and geometrical tolerances required. A full-scale manifold was produced on the Arcam A2 system (nearly 12 inches tall). A portion of the manifold was also produced in the Arcam Q10 system. Although a full scale manifold could not be produced in the system, a full scale manifold is expected to have similar material properties, geometric accuracy, and surface finish as could be fabricated on an Arcam Q20 system that is capable of producing four full scale manifolds in a production environment. In addition to the manifold, mechanical test specimens, geometric tolerance artifacts, and microstructure samples were produced alongside the manifold. The development and demonstration of these two key components helped Eaton understand the impact additive manufacturing can have on many of their existing products. By working within the MDF and leveraging ORNL's manufacturing and characterization capabilities, the work will ensure the rapid insertion and commercialization of this technology.
\end{abstract}

\title{
1. FEASIBILITY AND TESTING OF ADDITIVE MANUFACTURED COMPONENTS
}

This phase 1 technical collaboration project (MDF-TC-2015-069) began on March 30, 2015 and was completed on April 30, 2016. The collaboration partner Eaton Corporation is a large business. Two components were successfully fabricated using appropriate AM technologies based on the geometry and tolerances required for the component. The components were evaluated by Eaton and demonstrated the limiting feature size that can be created with the Renishaw Direct Metal laser Melting (DMLM) process in CoCrMo and, the feasibility of removing partially sintered material left by the ARCAM electron beam melting (EBM) process in intricate internal passageways.

\subsection{BACKGROUND}

The objective for this project is to identify two existing products and demonstrate manufacturability and the impact (cost, lead time, weight reduction) that AM can have on component performance. The first part that was evaluated is an arc flash interrupter. The role of this component is to improve safety and reliability of circuit breakers by quenching the arc. This component is approximately $25 \times 38 \times 64 \mathrm{~mm}$ in size with minimum feature dimensions of approximately 200 microns. Eaton provided both models and minimum feature variability. The second component that was evaluated was a complex hydraulic manifold. This specific part has numerous complex features that encompass many existing products in Eaton's product line. The most concerning of these are small diameter, internal pass-through channels that communicate hydraulic pressure and flow. 
ORNL manufactured these components and provided information related to the manufacture of the different components using two AM technologies; Renishaw laser powder bed processing and Arcam electron beam melting. The goal of the project was for ONRL was to work with Eaton to help them understand the geometrical limitations of the different AM technologies and to help understand the manufacturing steps associated with each process. In addition, ORNL provided information related to computer file manipulation and file preparation, machine setup, build rates, completion success rates for the machines, cool down time, and post processing requirements for the different processes. This information is critical for Eaton to understand what components in their product line could potentially be manufactured through additive manufacturing techniques.

Eaton then evaluated these components for material quality, geometric accuracy, and mechanical properties and subsequent potential for insertion of these materials into service.

\subsection{TECHNICAL RESULTS}

\subsubsection{Fabrication of Flash Interrupters:}

The flash interrupter chosen for the project is used to improve safety and reliability of circuit breakers by quenching the arc. This component is approximately $25 \times 38 \times 64 \mathrm{~mm}$ in overall size with minimum feature dimensions of approximately 200 microns. Because the feature dimensions associated with the wall thickness and the spacing between the walls were on the order of several hundred microns, the Renishaw laser powder bed system was chosen to fabricate these components. This was considered necessary for two reasons. First, the powder in the passages between the wall sections must be completely removed. During EBM, the powder bed is kept at an elevated temperature, therefore sintering the powder. This powder becomes difficult to remove, especially in small passageways. In addition, the size of the passages in these components is on the order of the size of the powder particles, significantly increasing the probability of having entrapped powder. Laser powder bed systems do not use an elevated temperature powder bed and therefore have a lower probability of leaving entrapped powder. Second, the electron beam melting technology does not have the feature resolution required to make these components. The typical wall thickness limitations for the EBM technology is $\sim 500$ microns while the laser wall thickness can be closer to 200 microns or smaller.

A total of 12 arc flash interrupters were fabricated from CoCrMo powder on a Renishaw AM$250(\mathrm{~N})$ laser powder bed system. Ten parts were fabricated in the vertical orientation and two parts were fabricated with the long axis 45 degrees to the build direction. The components were fabricated with various internal wall spacing to determine the limitations of the machine and to ensure that a successful component could be tested.

Figure 1 is a representation of non-proprietary components showing the minimum wall feature size and the minimum spacing achievable in the laser powder bed system using $316 \mathrm{~L}$ stainless steel powder. 

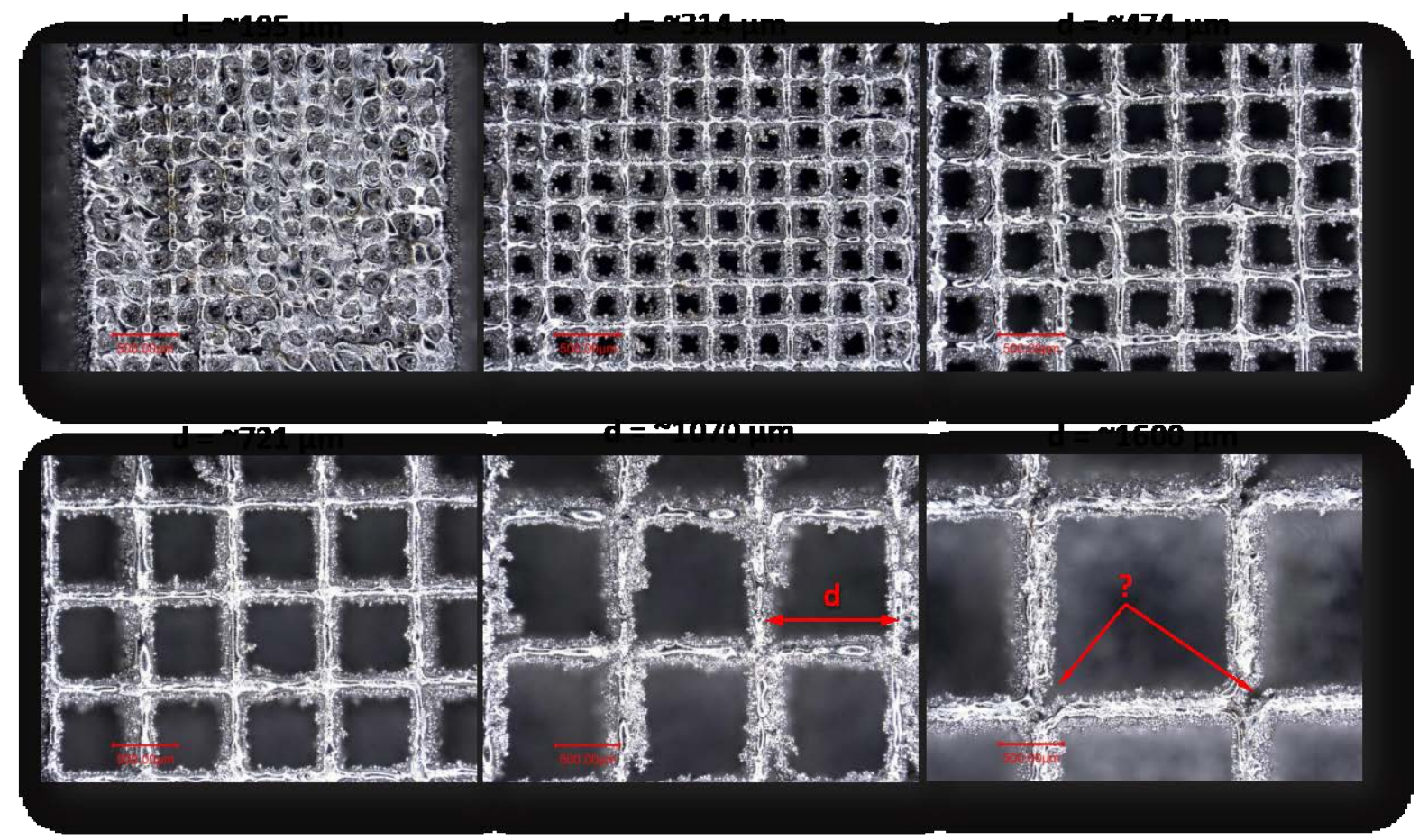

Figure 1: Minimum wall spacing achievable in the Renishaw laser powder bed system using 316L stainless steel powder.

In Figure 1 it is shown that the minimum wall thickness achievable with the laser powder bed system is on the order of 200 microns. This is nearly identical to the size scale requirements placed on the arc flash interrupters by Eaton for the project. The minimum spacing of the wall achieved in the current project was $\sim 314$ microns. When the spacing is reduced below this, the geometric accuracy of the component does not meet specification. This can be observed in the top row, far left image of Figure 1. In this processing condition, one can no longer distinguish between the wall and the passage of the component.

With respect to the Eaton arc flash interrupters, Eaton found that:

- The nominally required web wall thickness of 400 microns was achieved

- The nominally required web to web gap spacing of 200 microns was not achieved

- The internal wall surface roughness was found to be 60 microns Rz and approximately equal to the mean powder size (53 microns). This level of roughness may enhance heat transfer.

- Based on the process specifics, the estimated production cost was determined to be approximately $100 x$ that of a stamped metal assembly, making the application economically unattractive.

\subsubsection{Fabrication of Manifold using Electron Beam Melting:}

The second part evaluated was a complex hydraulic manifold. This manifold has numerous complex features that encompass many existing products in Eaton's product line. Eaton 
provided solid models (Solidworks, STL and STEP) of the manifold. In addition to the manifold, a geometric test artifact was designed by Eaton in order to examine the ability of EBM to produce small features, through holes, and complex internal passages. In addition to the manifold and the test artifact, additional mechanical test coupons (both dog bone and round tension geometries) were built. The layout of the build is shown in Figure 2 in both the isometric view and the top down view.
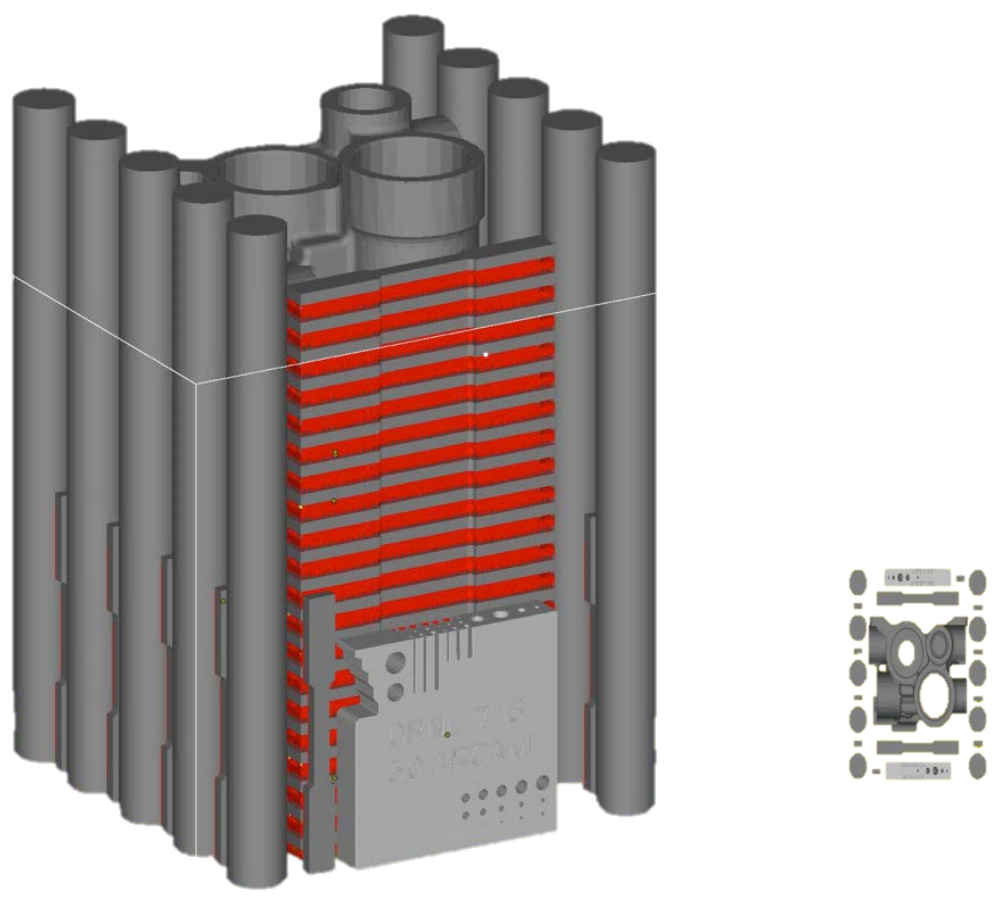

Figure 2: Layout within the EBM chamber for the manifold, tensile bars, and geometric test artifact

ORNL fabricated two of these build layouts, one for demonstration, one for destructive testing and provided Eaton build-specific information such as the time required for file preparation (support structures, part layout, slicing), machine preparation (loading files, material and part initiation), build and post processing time (cool down time, power and part removal and recovery). The first build was conducted on the Arcam A2 machine because it has a maximum allowable $z$ height travel of $320 \mathrm{~mm}$ and therefore could fabricate a full-scale manifold. The second build was fabricated on the Arcam Q10 system. This system has a $z$ height travel limitation of $\sim 180 \mathrm{~mm}$. Therefore, a full-scale build could not be completed. Instead, the identical file was loaded into the build chamber and a partial build was completed. This allowed Eaton to compare the geometric accuracy and surface finish between the two EBM systems. In a production environment, four full size manifolds are expected to fit into a larger Arcam Q20 system which duplicates the accuracy and surface finish characteristics of the Q10. The Q20 would provide Eaton with a more efficient and readily available production manufacturing platform for the manifolds.

A full EBM Control Build Report was generated by ORNL and supplied to Eaton for the build in the $A 2$ system. The process time for the build was 71 hours, heating of the start plate was 1 hour 22 minutes, and the cool down time was 7 hours and 38 minutes for a total build time of 
80 hours and 1 minutes. The build was run on the $A 2$ with software version 3.2.142 using Ti$6 \mathrm{Al}-4 \mathrm{~V}$ powder from Batch P866 supplied by Eaton. It is difficult to estimate the time savings that could be achieved by not producing test artifacts and material testing coupons alongside the component however it was estimated that the build would be approximately 40 percent faster if only the manifold was produced. For the manifold produced on the Q10 system, a similar build time to the $\mathrm{A} 2$ would be expected. Internal reports from Arcam have also shown that the Q20 system can be up to 40\% faster than using the A2 or Q10 systems. This comes from improved scan strategies and slightly larger layer thickness than the current systems. Therefore, the estimated time on the Q20 machine to produce a single manifold could be as low as approximately 20 hours.

In addition to the log files collected during the build process, ORNL captured in-situ images during the build process on the Q10 system. These images were provided to Eaton in order to demonstrate the ability to link in-situ process monitoring with build quality, mechanical test sample performance, and overall component reliability. An Eaton representative visited the MDF for a week in order to learn about the Arcam process and to oversee the setup, fabrication, and clean-up of a manifold build in the Q10 system. Eaton was briefed on future efforts related to part certification and qualification ongoing at ORNL.

As part of the evaluation process, Eaton first inspected the A2 manifold for open internal fluid passageways. Passages below $10 \mathrm{~mm}$ in diameter were found to be plugged and several approaches using mechanical tools and high intensity ultrasonic fluid agitation were used in an attempt to clear them. However, none of the methods used were successful due to the multiple abrupt angle turns that some of these passages make through the manifold. As a result, passages smaller than $5 \mathrm{~mm}$ diameter remained plugged.

Microstructural analysis was also performed on the tensile specimens as well as several adjacent cylindrical material coupons. The as-grown cylindrical coupons showed a rim of voids approximately $1 \mathrm{~mm}$ inboard of the parts external periphery. A majority of the observed porosity was removed following hot isostatic pressing of the specimens. See Figures 3a through 3d.
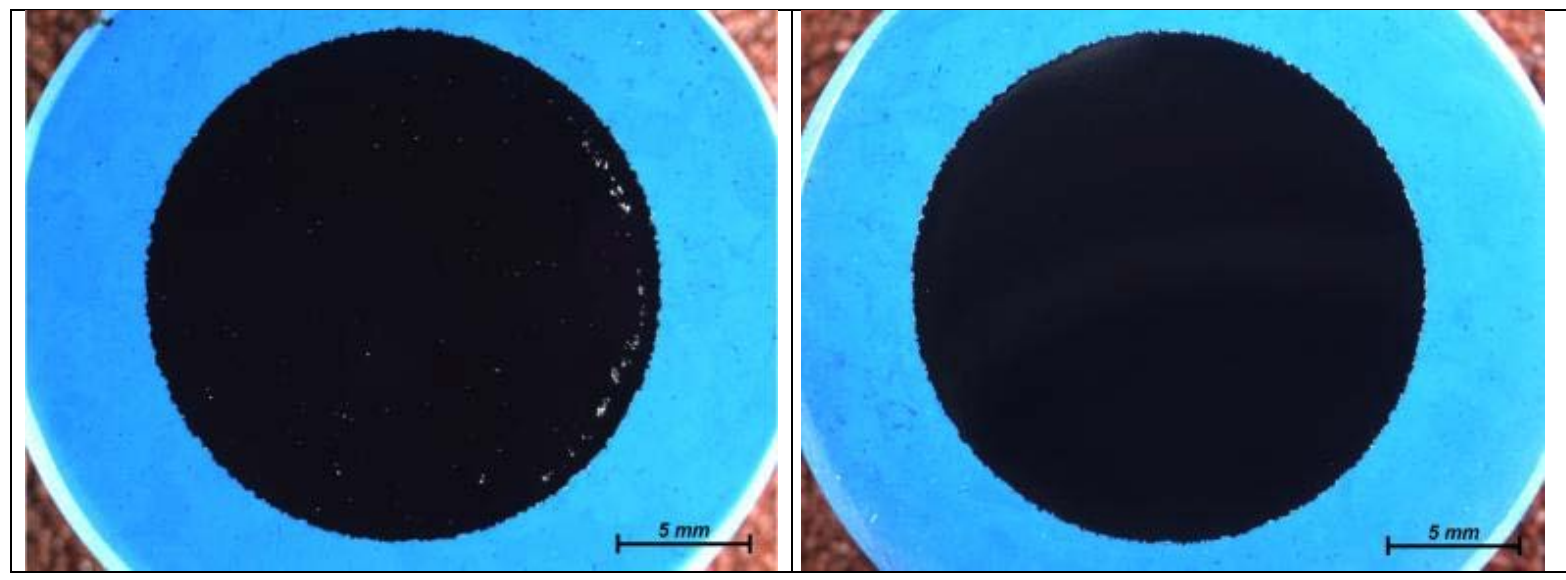


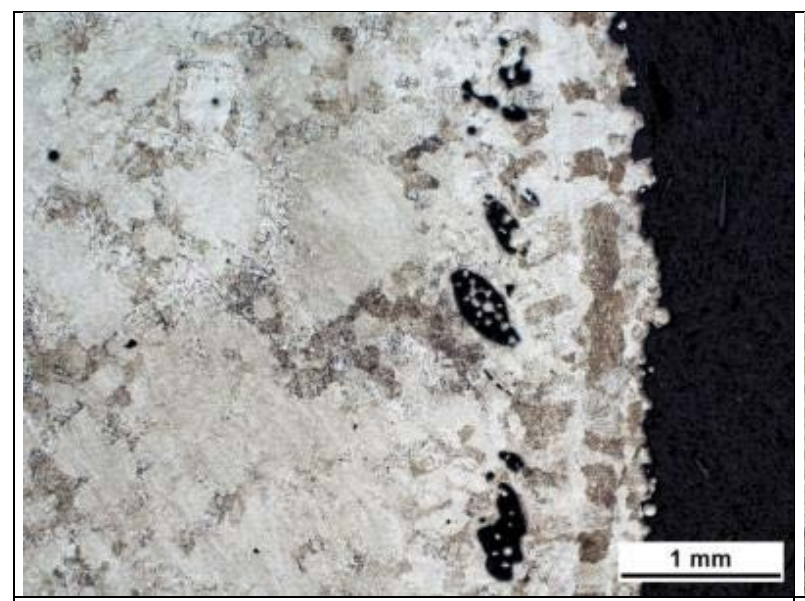

Figure $3 \mathrm{a}$ and $3 \mathrm{~b}$ : Observed porosity near the sectioned base of the $A 2$ vertically grown cylindrical specimen before HIP. Shown is an X-Y section perpendicular to the specimen grow direction. Significant porosity is evident approximately $1 \mathrm{~mm}$ inboard of the outside diameter.

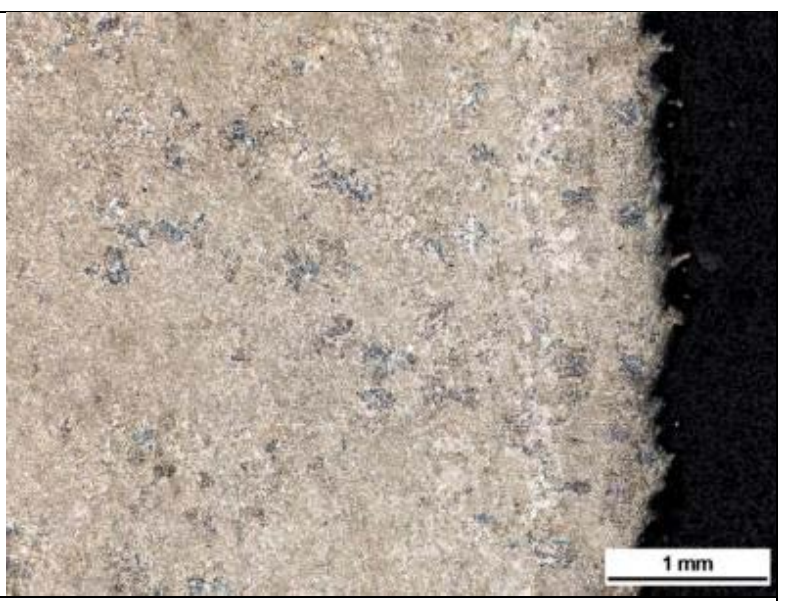

Figures $3 c$ and $3 d$ : Observed porosity near the base of $A 2$ vertically grown cylindrical specimen after HIP. Shown is an X-Y section perpendicular to the specimen grow direction. The observable porosity at the rim of the specimen is entirely eliminated; only 2 or 3 small remnant pores were found to remain elsewhere in the section.

Figure 3: Microstructural analysis of tensile samples for porosity before and after HIP.

Eaton also tested as-grown and subsequently hot isostatic pressed $\left(920^{\circ} \mathrm{C}, 100 \mathrm{MPa}\right.$ for $2 \mathrm{hrs}$.) tensile specimens to determine nominal mechanical properties. The averaged data (based on 5 specimens per condition) is shown in Figures $4 a$ and $4 b$.

Figure $4 \mathrm{~b}$ in particular normalizes and scales the data against Eaton target values. The targets are based on current Metallic Materials Properties. Development and Standardization (MMPDS) minimums for Ti6Al4V wrought material and the values shown in Figure $4 \mathrm{~b}$ represent the percent above or below those targets. As indicated in Figure $4 \mathrm{~b}$, as built specimens generally met target values for ultimate and yield strength, but were below target values for elongation at break. There was a significant improvement in ductility to above target values following the HIP process, but with some loss in strength. In general, the strength of the HIP processed Ti6Al4V fell 1-12\% below target values.

The significant increase in ductility and loss in strength is in-line with industry experience and overall expectations for the HIP process. However, these builds fell below the results published by ARCAM. While additional analysis is needed to assess root cause, it is likely that further optimization of the EBM or subsequent heat treatment processes could yield the needed improvements. 


\begin{tabular}{|c|c|c|c|c|c|c|c|c|c|c|c|c|}
\hline \multirow{3}{*}{\begin{tabular}{|l} 
Condition \\
Orientation \\
\end{tabular}} & \multicolumn{4}{|c|}{ Arcam EBM A2 } & \multicolumn{6}{|c|}{ Arcam EBM Q10 } & \multirow[t]{3}{*}{$\begin{array}{c}\text { Eaton } \\
\text { Targets } \\
\text { (MMPDS) }\end{array}$} & \multirow[t]{2}{*}{$\begin{array}{r}\text { Arcam } \\
\text { Reportec } \\
\text { Typical }\end{array}$} \\
\hline & \multicolumn{2}{|c|}{ As built } & \multicolumn{2}{|c|}{ After HIP } & \multicolumn{3}{|c|}{ As built } & \multicolumn{3}{|c|}{ After HIP } & & \\
\hline & $\mathrm{HE}^{*}$ & V & $\mathrm{HE}$ & V & $\mathrm{HE}$ & V & $\mathrm{HF}^{* *}$ & $\mathrm{HE}$ & V & $\mathrm{HF}$ & & \\
\hline UTS, MPa & 947 & 901 & 869 & 818 & 885 & 878 & 974 & 860 & 798 & 885 & 896 & 1020 \\
\hline $\mathrm{YS}, \mathrm{MPa}$ & 886 & 848 & 799 & 752 & 813 & 829 & 910 & 775 & 730 & 810 & 827 & 950 \\
\hline Elong. \% & 6 & 5 & 9 & 10 & 10 & 6 & 7 & 11 & 10 & 11 & 8 & 14 \\
\hline RA, \% & 6.8 & 4.5 & 7.9 & 12.8 & 9.7 & 8.9 & 8.2 & 9.3 & 12.7 & 10 & & \\
\hline
\end{tabular}

Figure 4a. Tensile Data collected from A2 and Q10 builds.

HE*: Horizontal on Edge

$\mathrm{HF}^{* *}$ : Horizontal Flat

\begin{tabular}{|c|c|c|c|c|c|c|c|c|c|c|c|c|}
\hline \multirow{3}{*}{$\begin{array}{l}\text { Condition } \\
\text { Orientation }\end{array}$} & \multicolumn{4}{|c|}{ Arcam EBM A2 } & \multicolumn{6}{|c|}{ Arcam EBM Q10 } & \multirow[t]{3}{*}{$\begin{array}{l}\text { Eaton } \\
\text { Targets } \\
\text { (MMPDS) }\end{array}$} & \multirow[t]{2}{*}{\begin{tabular}{|c|} 
Arcam \\
Reported \\
Typical \\
\end{tabular}} \\
\hline & \multicolumn{2}{|c|}{ As built } & \multicolumn{2}{|c|}{ After HIP } & \multicolumn{3}{|c|}{ As built } & \multicolumn{3}{|c|}{ After HIP } & & \\
\hline & $\mathrm{HE}^{*}$ & V & $\mathrm{HE}$ & V & $\mathrm{HE}$ & $\mathrm{V}$ & $\mathrm{HF}^{* *}$ & $\mathrm{HE}$ & $\mathrm{V}$ & $\mathrm{HF}$ & & \\
\hline UTS, MPa & 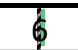 & 1 & $-\beta$ & $\sqrt{\theta}$ & -1 & -2 & 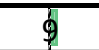 & -4 & -11 & -1 & $\phi$ & 14 \\
\hline $\mathrm{YS}, \mathrm{MPa}$ & 7 & 3 & $-B$ & $\sqrt{9}$ & -2 & $\phi$ & 10 & -6 & -12 & -2 & $\phi$ & 15 \\
\hline Elong. \% & -25 & -38 & 13 & 25 & 25 & -25 & -13 & 38 & 25 & 38 & $\phi$ & 75 \\
\hline \multicolumn{13}{|c|}{ 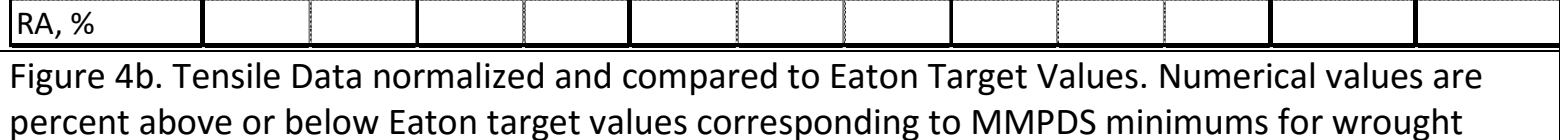 } \\
\hline $\begin{array}{l}\text { Figure } 4 \mathrm{~b} . \mathrm{T} \\
\text { percent abc } \\
\text { Ti6Al4V. } \\
\mathrm{HE}^{*} \text { : Horizo } \\
\mathrm{HF}^{* *} \text { : Horiz }\end{array}$ & $\begin{array}{l}\text { רsile }[ \\
\text { e or b }\end{array}$ & ata ne & $\begin{array}{l}\text { nali } \\
\text { on } t\end{array}$ & anc & $\begin{array}{l}\mathrm{mp} \\
\mathrm{esc}\end{array}$ & $\begin{array}{l}\text { d to } \\
\text { espc }\end{array}$ & $\begin{array}{l}\text { aton T } \\
\text { ding tc }\end{array}$ & $\begin{array}{l}\text { get } \\
\text { MM }\end{array}$ & $\begin{array}{l}\text { lues } \\
\text { S mi }\end{array}$ & $\begin{array}{l}\text { ume } \\
\text { num }\end{array}$ & $\begin{array}{l}\text { ical value } \\
\text { for wrou }\end{array}$ & $\begin{array}{l}\text { S are } \\
\text { ght }\end{array}$ \\
\hline
\end{tabular}

Figure 4: Mechanical properties of EBM processed Ti-6Al-4V samples

As an additional check on outcomes, $\mathrm{X}$-ray diffraction was used to measure residual stress on select specimens and the manifolds themselves. Measured surface stresses on the as-built specimens and manifolds were found to be compressive (a welcome result) but after HIP, were slightly tensile. Additional work to understand the mechanics of this result is also still needed.

Finally, given the ORNL provided processing times, Eaton performed an economic comparison against the current manufacturing method used to produce the manifold. That analysis showed a roughly $5 \%$ cost advantage for the EBM grown manifold.

\subsection{IMPACTS}

Based on a limited yet sufficient set of manufactured specimens, ORNL allowed Eaton to assess the technical and economic viability of two very different component geometries using two different additive manufacturing technologies.

For a finely featured Arc flash suppression device grown using DMLM, ORNL did not achieve the geometry that was required. The results did however provide Eaton with the data needed to evaluate other slightly less fine featured designs. In addition, and based on ORNL supplied process 
information, an economic model was assembled that allowed Eaton to estimate likely production costs. And while the cost of an AM produced arc flash suppressor was found to be unacceptably high, the cost model and process knowledge associated with determining cost will allow Eaton to evaluate and identify other applications that are better economically suited to the DMLM process.

With respect to the aerospace hydraulic manifold grown using ARCAM EBM, the difficulty associated with clearing of partially sintered powder from small and non-straight internal passageways was evaluated. For products of similar design, Eaton learned that the passageways will need to be straightened and/or enlarged to allow for clearing. Alternatively, this information also suggests that DMLM may be the better process. Based on this experience, Eaton has now separately processed several DMLM manifolds and is currently pursuing DMLM as the default process for these types of products.

\subsection{CONCLUSIONS}

For the arc flash suppression device produced using DMLM, the inability to replicate 200 micron features and a much higher cost associated with DMLM over sheet metal stamping, showed the arc flash interrupter it to be an unacceptable match to current generation DMLM production equipment. The lessons from that activity are now however being used by Eaton to evaluate other fine featured parts for viability.

For the hydraulic manifold produced using powder bed EBM, clearing of partially sintered powder from internal passageways was found to be an insurmountable problem. This reinforced Eaton's decision to move to the DMLM process which it is now pursuing for production of similar manifolds. 


\section{PARTNER BACKGROUND}

Eaton Corporation is a $\$ 22 \mathrm{~B}$ company that manufactures components for the power management industry (fluid, electric, transportation). Many of their products are extremely complex leading to high costs and lead times. Eaton is interested in exploring the impact Additive Manufacturing (AM) can have on reducing cost and lead times across their product lines. In addition, Eaton foresees using additive manufacturing in the near term to reduce development cost and time for tooling. The first of Eaton's businesses expected to adopt AM for serial production is its aerospace business. 